\title{
HISTORIOGRAFÍA CHILENA: CUATRO MOMENTOS DE LA EDUCACIÓN
}

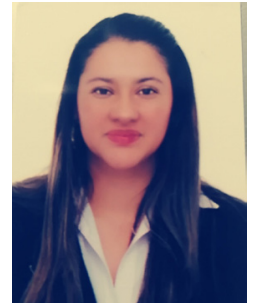

Fecha de recepción:10/08/2019
Fecha de revisión:25/09/2019

Fecha de aceptación:10/10/2019
Jazmín Alvarado González ${ }^{\mathbf{1}}$

Corporación Universitaria Republicana, Chile

jazmagalvarado@hotmail.com

\section{RESUMEN}

El presente artículo pretende generar un acercamiento general a las cuestiones historiográficas, al alrededor de la educación en Chile, iniciando desde el periodo de la independencia, posteriormente la dictadura, dando paso a la concertación como una época de implementación de cambios propuestos por los militares, presentando importantes modificaciones hasta el 2005 y por último, los logros más destacados posteriores al 2005 en articulación con los acuerdos establecidos por la UNESCO 2000, generando así una aproximación a la educación y los elementos que le han antecedido.

Palabras clave: educación, reforma, estatuto docente, dictadura, concertación, gremio, avances.

\section{CHILEAN HISTORIOGRAPHY: FOUR MOMENTS OF EDUCATION ABSTRACT}

This article aims to generate a general approach to historiographical issues, around education in Chile, starting from the period of independence, then the dictatorship, giving way to the agreement as a time of implementation of changes proposed by the military, presenting important modifications until 2005 and finally, the most outstanding achievements after 2005 in articulation with the agreements established by UNESCO 2000, thus generating an approach to education and the elements that have preceded it.

Key Words: education, reform, teaching statute, dictatorship, concertation, guild, advances.

\footnotetext{
${ }^{1}$ El presente artículo es resultado del proyecto de investigación, titulado: "Un acercamiento a las propuestas epistemológicas del siglo XXI en América Latina: repensar la región desde la educación, la familia y el desarrollo humano.", financiado por la Corporación Universitaria Republicana.

Decana e Investigadora Facultad de Trabajo Social Corporación Universitaria Republicana
} 


\begin{abstract}
Chile es el país latinoamericano más alejado de los centros de civilización occidental del Atlántico Norte. No obstante, entre todas las naciones latinoamericanas Chile parece haber experimentado la evolución política que más se aproxima a los patrones establecidos en las naciones industrializadas del área del Atlántico Septentrional. (Bergquist 1988:47)
\end{abstract}

\title{
INTRODUCCIÓN
}

Los países de América Latina, se han ido definiendo, desde sus combinaciones históricas: la geografía, la economía, la posición astronómica, las variaciones étnicas, la política, entre otras, han incidido en que, a pesar del reconocimiento de los múltiples orígenes comunes, se reconozca como una de las regiones más diversas del planeta. Si bien es cierto,

la experiencia colonial compartida, como divisiones de los imperios español y portugués, fue decisiva al forjar los destinos económicos y políticos de las nuevas repúblicas después de la Independencia. El patrón de desarrollo del siglo XIX, basado en la exportación de riquezas naturales a los países industrializados, reforzó esa sensación de compartir un pasado (Bulmer 1998: 11),

No es menos cierto, que hubo particularidades que fueron definiendo el carácter y las condiciones de cada nueva República Bulmer (1998) "los gobiernos de Argentina y Chile [por ejemplo,] emprendieron guerras contra sus poblaciones indias, en un esfuerzo por extender las fronteras de las nuevas repúblicas sobre tierras dominadas por pueblos indígenas que no habían sido sometidos por España" decisiones coloniales que aun permean en la actualidad, en especial en factores como el crecimiento económico y la calidad de vida, encontrando que estas desigualdades se han naturalizado, así mismo, evidenciando que las dinámicas políticas se han aunado con las económicas, privilegiando la mercantilización, por encima de la equidad, bajo el paradigma de distribución.

Los estudiosos de la situación latinoamericana han coincidido en la necesidad de buscar las causas estructurales de los problemas, éste adjetivo asume que la situación presente es el único horizonte de realidad pensable, asumiendo el principio de plenitud posicionado por Leibniz sin embargo, las Ciencias Sociales han aportado en el análisis de la situación de la región, a partir de elementos constitutivos. Así, se ha entendido que la Sociedad y el Estado se imbrican en la articulación económica; que las clases antagónicas: terratenientes, burguesía y proletariado se transforman conforme se reformula la producción capitalista. 
Cada país de la región, es una interesante propuesta de análisis en esta materia, sin embargo, Chile a pesar de tener una economía colonial en su fundación, de acuerdo con la Informe de Desarrollo Humano ha superado obstáculos propios del subdesarrollo mostrando importantes signos de progreso, que no solamente la han estabilizado, sino que le han permitido avanzar, en comparación con otros estados latinoamericanos, y en general a nivel mundial. Lamentablemente, estudiar la evolución completa de esta nación sería una tarea titánica, por lo que se hace necesario establecer una acotación, la cual será comprendida desde 1540 cuando Pedro de Valdivia nombró Nueva Extremadura a la región de Copiapó, pasando por los acontecimientos alrededor de la Batalla del Río Lircay en 1830 y otros muy relevantes momentos del proceso de independencia chilena, los cuales han configurado el carácter chileno, acontecimientos que han generado cambios coyunturales y estructurales, como antecedentes de la dictadura en 1973, que necesariamente deberá mostrarse como una ruptura respecto al sistema existente hasta entonces; Seguidamente los cambios propuestos por los militares hasta el 2005 cuando caducaron o presentaron importantes modificaciones y por último los cambios más destacados posterior al 2005 en articulación con los acuerdos establecidos por la UNESCO en el año 2000, momentos en los que se estudiara de manera articulada la educación con relación a algunos elementos socio-historiográficos que han incidido en ella.

\section{Primer Momento: La independencia escenario de consolidación de la identidad estructural chilena mediante reforma agraria y administración de la educación.}

Analizando varios escenarios de la historia chilena, Ansaldi y Giordano (2012) "en referencia a periodos anteriores a 1973, evidencian que la presidencia de Eduardo Frei Montalva ${ }^{2}$ muestra dos procesos bastante relevantes: la reforma agraria y la sindicalización de los trabajadores rurales, posteriormente, Salvador Allende ${ }^{3}$ recoge los frutos del fracaso del proyecto de la Democracia Cristiana, por lo que Chile

"se distinguió en 1970 eligiendo el primer jefe de Estado marxista en el Hemisferio Occidental.... Entre ambos gobiernos consolidaron el sistema de partidos políticos, imitación de los modelos europeos, que al institucionalizarse representaban las diferentes fuerzas sociales chilenas" (Bergquist, 1988: 48)

El proletariado se fue organizando en torno a la "mancomunalidad", que fue el desarrollo del sindicalismo y la mutualidad, creando un binarismo social entre la "clase explotadora blanca y las

\footnotetext{
${ }^{2}$ Presidente chileno por el partido Demócrata Cristiano entre el 3 de noviembre de 1964 y el 3 de noviembre de 1970, murió en 1982.

${ }^{3}$ Presidente chileno por el partido Socialista de Chile entre el 4 de noviembre de 1970 y el 11 de septiembre de 1973, se suicidó después del bombardeó a la Casa de la Moneda.
}

ORATORES ISSN Impreso: 2644-3988 ISSN Electrónico: L-2644-3988 Año 7. Número 11. Diciembre 2019 - Mayo 2020 
clases explotadas mestizas e indígenas." (Ansaldi y Giordano, 2012: 605), así mismo de acuerdo con Víctor Bulmer-Thomas, (1988) hacia mediados del siglo XIX,

"muchos gobiernos latinoamericanos favorecieron también el establecimiento de colonias agrícolas de inmigrantes europeos. En su mayor parte fracasaron, pero algunas del Cono Sur -especialmente del sur de Chile, el sur de Brasil y el sur de Argentinatuvieron notable éxito." (111)

A pesar de la agitada dinámica política, Álvarez (2007) "En 1938 se daría inicio a un nuevo período de la historia de la política en Chile, al momento de la llegada al poder de Pedro Aguirre 4 apoyado por el Frente Popular y parte del Partido Radical. Éste adoptó una actitud paternalista, fomentando la educación", así mismo la economía chilena fue consolidándose, tal vez porque tomaron en serio los 5 puntos del programa reformista planteado Pedro Aguirre de la Cerda, Bulmer- (1988)

proponía la realización de cinco puntos: 1) nacionalización de las minas de carbón, cobre y salitre, y de las principales industrias manufactureras; 2) control estatal del comercio exterior y el crédito; 3 ) impuesto progresivo a la renta de la tierra; 4) reorganización de la enseñanza pública, y 5) obligatoriedad del trabajo (606)

De la comparación de las diferentes fuentes, se puede colegir que esta decisión dio paso a dos realidades comunes que transversalizaron la definición de la identidad estructural chilena a través de la historia: la primera la reforma agraria (que en muchas ocasiones fue más una redefinición de la territorialidad) y la segunda la administración de la educación.

Respecto al primer aspecto, las reformas cualitativas promovieron la transformación de la sociedad, desarticulando lo que Ansaldi y Giordano (2012) llaman "las bases de la dominación oligárquica" como resultado de un proceso contralatifundista, que promovió la organización campesina a través de cooperativas, favoreciendo la propiedad de las familias, Bergquist, (1998) "generando modificaciones importantes en la demanda de obreros, a medida que avanzaba la tecnificación del campo".

Generalizando, con Víctor Bulmer-Thomas (1994), hay que reconocer que "la diversidad geográfia y geológica de América Latina hizo que cada república tuviese una gama limitada de productos de exportación. Chile, país templado, pudo exportar trigo, pero no café; tenía enormes depósitos de cobre, pero poco petróleo". Más adelante puntualiza que "Chile, bajo la austera

${ }^{4}$ Presidente chileno por el Partido Radical entre el 3 de noviembre de 1938 y 1941 año en el que murió antes de concluir su periodo presidencial, logro su reconocimiento por el liderazgo del frente Nacional y la promoción de la educación popular. 
influencia del conservador Diego Portales 5 , aplicó una serie de reformas que forzaron la expansión del comercio exterior, gracias a la contribución de las exportaciones de cobre y de plata.” (60)

En cuanto a lo relacionado con la administración de la educación, una de las principales razones radico en haberla puesto en el eje de las discusiones sobre lo público, cada aspecto estructural de la educación se ha ido revisando hasta consolidar el actual sistema educativo, el mismo que es cuestionado permanentemente, por su parte el gobierno del Presidente Salvador Allende (1970-1973),

Asignó a educación los más altos recursos financieros del período, adelantó la expansión educativa y avanzó en la política de igualdad de oportunidades. Profundizó la desconcentración del aparato estatal de educación, a través de las Coordinaciones Regionales de Educación y quiso desburocratizarla y hacerla participativa, a través de los Consejos Regionales y Locales de Educación. Sin embargo, su gestión se vio entrabada por la rigidez del conjunto de la institucionalidad estatal y, sobre todo, por el clima de conflicto social e ideológico que rodeó su prematuramente interrumpida gestión. (Núñez 1997: 14)

\section{Segundo momento: la dictadura momento de cambios de la educación chilena vía sindicalización}

Después de 1950 países como Argentina, Brasil, Chile, Colombia, México y Uruguay empezaron a consolidarse como puntas de lanza en la subregión, dando comienzo a la época de industrialización de Latinoamérica, iniciando la monetización, la banca y la asunción de diferentes interpretaciones del modelo de desarrollo, que obligaron a la estructuración del Estado, bajo la égida de la modernización; proceso, que además consolidó los diferentes escenarios políticos y económicos nacionales, las cargas tributarias eran abrumadoras, los ciudadanos naturalizaron la lógica de la deuda para mediados de la década de los ochenta, viendo la necesidad de regular el cobro de intereses, tanto en las relaciones entre particulares, como en el ejercicio bancario, así como todo lo referente al crédito internacional, en las primeras fases de proceso de endeudamiento, el cobro de intereses se hizo desde prácticas de usura.

Las altas tasas nominales introdujeron una cuña entre los precios mundiales y nacionales, imponiendo una pesada carga a los consumidores. Pero para los productores los elevados

\footnotetext{
${ }^{5}$ Diego José Pedro Victor Portales y Palazuelos, nació el 16 de junio de 1793, fue asesinado el 6 de junio de 1837, ministro de Estado chileno, durante los gobiernos de José Tomás Ovalle (1829 - 1831 y 1830 - 1831) y Joaquín Prieto (1831-1836); se le reconoce la estructuración política del Estado chileno, así como se le critica el carácter dictatorial de sus discusiones.
}

ORATORES ISSN Impreso: 2644-3988 ISSN Electrónico: L-2644-3988 Año 7. Número 11. Diciembre 2019 - Mayo 2020 
gravámenes nominales no eran más que la mitad del problema. La medida crucial para ellos era el cambio de valor agregado por unidad de producción creado por el sistema proteccionista, tomando en cuenta no sólo el gravamen nominal sobre las importaciones competidoras, sino también el impacto de los aranceles y de otras formas de protección sobre el costo de los insumos. Esta medida, conocida como tasa efectiva de protección (TEP) ${ }^{6}$, fue un indicador más apropiado de los incentivos que se ofrecían a la industria. Por lo general la TEP fue aún más alta que la protección nominal para muchas clases de bienes, y particularmente elevada para los bienes de consumo. (Ansaldi y Giordano 2012: 326)

Este aumento en las tasas implicó la gestión de capital extranjero, bien con banca comercial o a través de estamentos multilaterales,

El giro de la estructura industrial hacia los productos de consumo duraderos y los bienes intermedios y de capital aumentó el tamaño mínimo de la inversión, y exigió un acceso a la tecnología que no siempre se podía obtener en el mercado abierto, (Ansaldi y Giordano 2012: 327)

estableciendo en los imaginarios colectivos el discurso de la necesidad de la tecnología en la vida de las personas y en el mejoramiento de los procesos de producción.

Parafraseando a Ansaldi y Giordano (2012) en este contexto de múltiples incertidumbres, el general Augusto Pinochet ${ }^{7}$ dirigió el golpe militar por el que fue bombardeado el Palacio de la Moneda el 11 de septiembre de 1973, destacando tres temas que marcaron su gestión: las violaciones a los Derechos Humanos en ejercicios represivos contra los opositores al régimen militar, las complejas relaciones internacionales que tejió para legitimarse, y sus políticas económicas, que aunque brutales, redundarían positivamente a largo plazo en Chile; Al anular la reforma agraria, restituir el 30\% de las tierras expropiadas a los terratenientes y poner en venta al $40 \%$ de las tierras de los campesinos, abrió paso a un esquema de agricultura capitalista, en el que los campesinos, pasaron a convertirse en obreros agrícolas, el desmonte progresivo del Estado se combinó con la privatización tecnocrática, redundando en lo que se ha conocido como "el milagro chileno", a costa de la "pauperización obrera" (Pg 408- 409, 440 a 442).

\footnotetext{
${ }^{6}$ La TEP se define como el cambio proporcional de valor agregado (por unidad de producción) debido al proteccionismo, en comparación con la situación en el libre comercio. (Nota de la autora)

${ }^{7}$ Presidente chileno por golpe de estado y dictadura militar entre el 11 de septiembre de 1973 y el 11 de marzo de 1990, en el ínterin entre el golpe de estado y su formalización como presidente, fue presidente de la junta militar del gobierno de Chile, cargo que detentó entre el 11 de septiembre de 1973 y el 11 de marzo de 1981, murió el 10 de diciembre de 2006, en medio de los debates jurídicos por su permanencia en instalación carcelaria y los procesos por desapariciones y otras violaciones a los Derechos Humanos.
} 
Así mismo, reaparecieron practicas feudalitas, lo que sin duda contribuyeron a la "pauperización obrera", privilegiando a grandes terratenientes poseedores de la tierra,

En un esfuerzo por garantizarse una fuerza laboral adecuada sin necesidad de aumentar sus salarios reales, muchos grandes terratenientes difundieron la práctica (existente desde los tiempos coloniales), de dar a los trabajadores acceso a la tierra a cambio de su trabajo. Estos campesinos, conocidos como inquilinos en Chile, (...) a menudo se encontraban prácticamente fuera de la economía monetaria, pues se les pagaba en especie, y no en efectivo. Aun los jornaleros, contratados durante el año para tareas específicas, solían estar al margen de la economía monetaria; esto ocurría cuando se daba crédito al trabajador, muchas veces en circunstancias dudosas, a cambio de sus labores futuras. La deuda no siempre quedaba cancelada con la muerte del deudor; podía pasar a sus hijos, por lo que a menudo se llama a este sistema servidumbre por deuda. (Bulmer 1998: 114-115)

En concordancia, resulta oportuno destacar que las ganancias producidas en la exportación permitieron cavilar la calificación de la mano de obra, entendiendo que

una fuerza laboral calificada y asalariada no sólo representa una concentración importante del poder adquisitivo para los vendedores en la economía no exportadora, sino también una fuente potencial de futuros empresarios que podrán llevar su capacidad y sus conocimientos a otras ramas de la economía. (Bulmer 1998: 29)

Por otra parte, con la aparición de la Comisión Económica para América Latina y el Caribe CEPAL $^{8}$ y la firma del Pacto Andino ${ }^{9}$ se fueron ampliando los conceptos asociados al desarrollo, cuando se engrosó el renglón de clase media, fue evidente que las familias requerían de instituciones escolares, tanto para la formación de clases dirigentes emergentes, desde el discurso de la movilidad social; Bulmer (1998) "la inscripción en las escuelas primarias y secundarias aumentaba con rapidez, tanto en términos absolutos como en relación con la población en edad escolar, y el analfabetismo iba en retroceso".

Cabe señalar que, en los procesos de privatización, que un Estado se la juegue por la productividad seriamente, implica apuestas de largo plazo, para el caso de Chile CLACSO (2005) "en los últimos años ha cobrado relevancia la teoría del capital humano" pensando en ofrecerle un sentido a la existencia de cada ser humano. Si se entiende que "la eficacia de la difusión está ligada

\footnotetext{
${ }^{8}$ Fundada el 25 de febrero de 1948.

${ }^{9}$ La Comunidad Andina inicia con el Acuerdo de Cartagena, el 26 de mayo de 1969; el nombre Pacto Andino se usó hasta el 2006, a partir de ese momento quedó como Comunidad Andina de Naciones - CAN.
} 
a la profundidad de los procesos educativos a los que está expuesta en promedio la población" así la medición de la industrialización del país, fue de acuerdo con el acceso y calidad a la educación; Sentido en el que la situación del Magisterio se puede explicar desde dos perspectivas:

Hasta 1973, el magisterio chileno-cuyos docentes, en su gran mayoría, eran funcionarios públicos dependientes del Ministerio de Educación, con la excepción de un mínimo porcentaje que trabajaba en el sector particular pagado y particular subvencionado-no sólo había logrado un legítimo reconocimiento social y profesional, sino que había sido capaz de ir ganando importantes espacios de participación en la generación de políticas educativas, como también un mejoramiento de sus remuneraciones, alcanzando los mayores niveles de renta entre 1970-1973. (CLACSO 2005: 12)

Con esfuerzo, Chile había logrado el reconocimiento de sus docentes en la nómina pública, sin embargo, acorde con el pensamiento neoliberal que no ve la educación como un derecho, sino como un gasto, el docente asumió grandes desventajas salariales, así como precariedad en su labor, para la estructura del capital: el obrero pauperizado consumidor.

El advenimiento de la dictadura significó profundos cambios. En los hechos, dio inicio a un violento descenso del gasto público en educación, lo que evidentemente repercutió en una fuerte baja de las remuneraciones docentes; se intervino la dirección de escuelas y liceos, y se limitó el desarrollo del currículo. Todo ello fue significando un tremendo deterioro de la educación que había sido, hasta principios de los 70, considerada de buena calidad en el concierto latinoamericano. (CLACSO 2005: 12)

En consecuencia, se evidencia que uno los grupos más fuertemente golpeados por la dictadura militar chilena, en todos los frentes, fue la docencia, quienes se organizaron para contrarrestar las medidas que socavaban su dignidad y su mediano bienestar, logrando la promulgación de una ley para proteger la libertad de sindicalización,

en el contexto de un cambio de la Ley de Colegios Profesionales, que decretó la libertad de asociación y la creación de asociaciones gremiales de inscripción voluntaria, en 1981 las organizaciones magisteriales de base se articularon a escala nacional, constituyendo legalmente la AGECH (Asociación Gremial de Profesores de Chile). La AGECH se transformó en el canal de expresión, resistencia y crítica a las políticas privatizadoras y fue la impulsora del retorno a la democracia en el país. en lo gremial, se destacó su temprana propuesta de Estatuto de la Profesión Docente (1981). (CLACSO 2005: 13)

Esta reorganización fue dando pie al posicionamiento de la protesta magisterial, lo que conllevo a que en 1997 se aprobaran algunas normas especiales para el personal docente, 
permitiendo recuperar algunos de los beneficios perdidos, posteriormente, dando tránsito hacia el restablecimiento de la democracia en Chile:

A partir de 1990, año en que se inició la transición hacia la democracia, el Colegio de Profesores se ha ido fortaleciendo como organización social. De los 140.000 docentes que atienden a los niveles de educación preescolar, básica y media, más de 80.000 pertenecen voluntariamente al Colegio y mantienen sus cotizaciones al día. Es, quizá, la más influyente y de mayor poder de todas las organizaciones sindicales existentes en el país. Aunque se enmarca, de acuerdo con sus estatutos, en una asociación gremial, las que legalmente no pueden negociar, en la práctica actúa como un sindicato nacional que negocia de hecho con el gobierno condiciones de trabajo y de remuneraciones para el conjunto de los docentes del país que trabajan en el sector municipal y particular subvencionado. (CLACSO 2005: 13)

Si bien es cierto que no se alcanzó el nivel salarial previo a la dictadura, el nuevo estatuto docente de 1991 empezó a ubicar la profesión en otro lugar, promoviendo cambios coyunturales que se extendieron hasta 1995

El Estatuto Docente estableció la Renta Básica Mínima Nacional (RBMN), que reguló el piso mínimo de sueldo de todo el magisterio en el ámbito nacional. Introdujo, además, las siguientes asignaciones salariales: años de servicio, alcanzándose el $100 \%$ de la RBMN con 15 bienios; perfeccionamiento, que fluctúa entre un 1\% y un $40 \%$ de la RBMN, según horas y tipo de perfeccionamiento que realice el profesor; trabajo en condiciones difíciles para los profesores que se desempeñan en escuelas aisladas, rurales o de alta vulnerabilidad social. También planteó el reconocimiento de la condición profesional del trabajo docente. (CLACSO 2005: 13)

Asimismo, el escenario que propicio el tránsito hacia el restablecimiento de la democracia en Chile, permitió fortalecer el sector educativo como organización social, a la vez que la reubicación de la profesión docente en un lugar más destacado y privilegiado,

A partir de 1990, año en que se inició la transición hacia la democracia, el Colegio de Profesores se ha ido fortaleciendo como organización social. De los 140.000 docentes que atienden a los niveles de educación preescolar, básica y media, más de 80.000 pertenecen voluntariamente al Colegio y mantienen sus cotizaciones al día. Es, quizá, la más influyente y de mayor poder de todas las organizaciones sindicales existentes en el país. Aunque se enmarca, de acuerdo con sus estatutos, en una asociación gremial, las que legalmente no pueden negociar, en la práctica actúa como un sindicato nacional 
que negocia de hecho con el gobierno condiciones de trabajo y de remuneraciones para el conjunto de los docentes del país que trabajan en el sector municipal y particular subvencionado.

El Estatuto Docente estableció la Renta Básica Mínima Nacional (RBMN), que reguló el piso mínimo de sueldo de todo el magisterio en el ámbito nacional. Introdujo, además, las siguientes asignaciones salariales: años de servicio, alcanzándose el $100 \%$ de la RBMN con 15 bienios; perfeccionamiento, que fluctúa entre un $1 \%$ y un $40 \%$ de la RBMN, según horas y tipo de perfeccionamiento que realice el profesor; trabajo en condiciones difíciles para los profesores que se desempeñan en escuelas aisladas, rurales o de alta vulnerabilidad social. También planteó el reconocimiento de la condición profesional del trabajo docente. (CLACSO 2005: 13)

Cabe señalar, que estos cambios coyunturales se promovieron hasta el año 1995, momento en el que se generó la concertación educativa.

\section{Tercer Momento: La Concertación Educativa hacia un proyecto educativo nacional}

La concertación educativa en Chile se refirió especialmente a la expansión del sistema de educación formal que tuvo ciertas características especiales, la primera en consideración a que Núñez (1997) "la matrícula educativa crece más rápidamente que la población de las edades escolares", de manera que aumenta la cobertura, pero no aumenta la razón de cupos demandados, desde aquí se deduce lo más impresionante de la historia de la educación chilena, la coherencia al buscar los objetivos nacionales, por encima de los sesgos ideológicos y de las muy conflictivas maneras de ejecutar la política.

Durante los gobiernos de los Presidentes González Videla, Ibáñez y Alessandri, esto es, entre 1950 y 1964 , el conjunto del sistema crece desde una cobertura de $26,2 \%$ hasta una de $35,8 \%$ de la población de $\mathrm{O}$ a 24 años de edad. En los siguientes once años -1964 a 1974- correspondientes a los gobiernos de los Presidentes Frei y Allende y al primer año del gobierno militar, la cobertura salta de 35,8 a 54,8\%. En 1990, al término del gobierno militar, había retrocedido hasta $51,2 \%$, pero en 1995 se detecta una tendencia al aumento de la cobertura a un 54,1\%. (Núñez 1997: 6)

Es así, como se libró paulatinamente una doble batalla al interior del sistema escolar respecto a la infraestructura y matrícula, con el tiempo, la preocupación giró hacia la enseñanza, la docencia

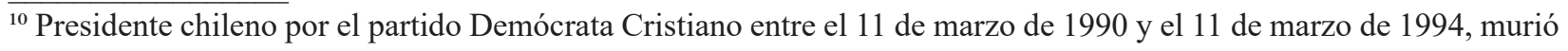
en 2016. 
y los resultados de los procesos académicos, vislumbrando "que, a pesar de todos los esfuerzos modernizantes, el nivel general de los aprendizajes en la educación básica era bajo y que éstos se distribuían de manera socialmente discriminatoria" (Núñez 1997:14); Eso viró la preocupación hacia los docentes y el currículo, de manera que fue necesario establecer una normativa para formalizar el proyecto educativo nacional.

En marzo de 1990, en los últimos días del régimen del general Pinochet se aprobó la Ley Orgánica Constitucional de Enseñanza, LOCE, que regulaba aspectos curriculares referidos a la educación básica y media, en dicha Ley se aprobaron objetivos generales para cada uno de ambos ciclos, muy similares a los adoptados por Decreto en 1980 y 1981. En la misma ley se estableció un mecanismo para hacer efectiva la libertad de enseñanza, a través de una profundización del principio de flexibilidad curricular ya introducido en 1980 y 1981. Otro aspecto de esta ley con incidencia en materias curriculares fue la norma que obliga al Ministerio de Educación a mantener sistemas de evaluación de la calidad de la enseñanza.

El valor más importante de la LOCE fue poner en mesa de discusiones todo el sistema educativo chileno, desarrollando encuentros con los docentes, fue en ese proceso analítico que empezó a socializarse la serie de situaciones que pusieron a la educación chilena en la esquina del comercio mercantilista, Nuñez (1997) “en 1977, el Ministerio de Educación se desprendió de buena parte de las escuelas o institutos de educación media técnico-profesional y los entregó a la administración de corporaciones privadas creadas por las asociaciones gremiales".

Pasar las responsabilidades propias de la gestión escolar a particulares y a las municipalidades reflejo una dificultad, la escasa o nula preparación que demostraban estos entes para las labores escolares, de manera que el Estado no pudo desligarse del todo de la administración de las escuelas, tanto por las subvenciones, como por la administración descentralizada de la misma,

Manteniéndose en el encuadre de las disposiciones de la Constitución y de la Ley Orgánica Constitucional de Educación, el gobierno del Presidente Aylwin (1990-1994 ), reinterpretó el rol del Estado redefiniéndolo en los hechos como un Estado activo, responsable y conductor, no obstante que ha preservado la arquitectura gruesa de la institucionalidad educativa descentralizada.

En la gestión educacional, hechos significativos han sido, por una parte, la dictación del Estatuto de los Profesionales de la Educación, que modificó de modo importante la administración del personal docente, y por otra, los cambios en el financiamiento público de la educación: se introdujo un sistema de reajustabilidad de las subvenciones que preservó su valor de año en año, 
aumentó lenta pero sostenidamente el gasto público y se estableció una modalidad de financiamiento que permite y favorece el aporte familiar en escuelas subvencionadas por el Estado. (Nuñez (1997: 16)

Demostrando que la preocupación por la calidad no puede quedarse en el currículo, sino que debe enfatizar en las condiciones laborales del docente, mediante el Colegio de profesores de Chile en CLACSO (2005) se iban estudiando las reformas educativas en los países del cono sur, como resultados parciales, han enviado informes coyunturales, tanto para la difusión de los elementos históricos y pedagógicos, como para atender a la evolución de las políticas públicas educativas en el contexto regional.

En primer lugar plantean que después de la dictadura, hay que encauzar correctamente la nación, en algún sentido se entiende que Chile debe ser refundado, desde las bases democráticas y constitucionales, como el tema más sensible, para esta época, es la sistemática y amplia violación de los Derechos Patricio Aylwin ${ }^{10}$ debió liderar esta tarea, en varios frentes que resultaban relevantes, aunque cada actividad asumida, generaba resquemores y avivaba dolores. Su gobierno debió lidiar con la pobreza desconocida hasta el momento en Chile, de modo que para el 2001, aunque la economía chilena iba por un camino inmejorable, el balance social requirió acciones urgentes respecto a los Derechos Humanos y las garantías constitucionales en todo el territorio chileno,

En los 90, la recomposición del "tejido social" dañado por la dictadura se convierte en un tema central para los sectores más progresistas de la sociedad. Sin embargo, es una tarea que aún continúa inconclusa. Basta mencionar, al respecto, la debilitada situación en que se encuentran los movimientos sociales o la baja credibilidad del sistema político en general. La rearticulación del tejido social implica abordar situaciones de distinta índole: revalorar la organización social, sindical y política; restablecer valores, principios y formas de convivencia más respetuosas; elevar la calidad de vida de las personas; recomponer el sistema político democrático, etc.” (CLACSO 2005: 7)

En este contexto se han realizado diversas acciones para mejorar la calidad de vida de la población: ajustes salariales en algunos sectores laborales, esfuerzos por organizar a la población a través de instituciones como el Fondo de Solidaridad e Inversión Social (FOSIS), reformas en el ámbito de la salud y educación, entre otras. El Estado aumentó el gasto social, introdujo políticas sociales compensatorias y realizó transferencias de recursos monetarios a la población más pobre a través de la focalización del gasto. Esto permitió reducir la pobreza entre fines de los 80 y fines de los 90, aunque continúa 
existiendo un núcleo de la población situada en los marcos de la "pobreza dura", según Clarisa Hardy y Pablo Morris, entre 1990 y 2000 la pobreza se ha reducido de 5 a 3 millones de personas, en tanto, la extrema pobreza habría disminuido de 1.600 .000 personas a 850.000 indigentes en el mismo período. (CLACSO 2005: 8)

Chile entendió esta situación y empezó un proceso de profesionalización salarial de los docentes, dentro de los esfuerzos reformistas, que ya habían empezado a llevarse a cabo, por parte de los mismos docentes y otros estamentos gubernamentales.

El desarrollo en Chile enfatiza la búsqueda de equilibrios en el plano macro económico, pero presenta al mismo tiempo profundas crisis y deterioros en la calidad de vida de amplios sectores sociales y del entorno natural. Lo anterior lleva a plantear la necesidad de examinar críticamente el modelo económico neoliberal, especialmente en sus efectos sobre los ciudadanos, los trabajadores y sus familias. (CLACSO 2005: 288)

En este sentido, en 1995 se llega a la revisión del estatuto docente; resultado de una serie de movilizaciones sociales, derivadas de desmejoras sustantivas en la política salarial magisterial; que reflejo: retroceso en la situación laboral de los docentes, aumento de las causales de despido (por salud incompatible, por supresión de horas, fusión de cursos o establecimientos), se disminuyó en dos semanas las vacaciones, se cambió la dotación docente por establecimiento a dotación docente communal; Mediante el establecimiento de el Plan Anual de Desarrollo de la Educación Municipal (PADEM), la adecuación de la planta docente de una comuna, se ajustó a las fluctuaciones de la matrícula, racionalizándose el personal contratado en función de los ingresos recibidos (CLACSO: 2005:14)

De acuerdo con la revisión del Estatuto, las negociaciones siguieron, de manera tal que lograron diferentes reconocimientos y avances en materia educativa, algunas de las cuales se relacionan a continuación:

\section{Tabla 1}

Avances a partir de revisión de Estatuto Docente 1995-2005

\section{Salariales y Prestacionales:}

- Aumento de los salarios a través del aumento de RBMN.

- Reajuste para el sector particular subvencionado a través de bonos que son financiados directamente por el Estado.

- Se obtuvo la jubilación con derecho a indemnización de 11 meses de remuneración a todo profesor o profesora en edad de jubilar. 
- Se consiguió poner en régimen 5.000 becas para hijos de profesores que ingresen a la educación superior, durante el tiempo que dure el estudio.

- Finalmente, se logró que todos los docentes que llevaban tres años continuos o cuatro años discontinuos a contrata, fueran profesores titulares.

- El cambio en la dependencia de los establecimientos educacionales; con el consiguiente trastorno del régimen laboral de los profesores, quienes pasan de un régimen funcionario a uno regido por el código laboral, y la forma de financiamiento, desde un subsidio a la oferta a uno de subvención a la demanda, se inició en 1981 con la municipalización de las escuelas, y ha avanzado sustancialmente hasta el presente.

\section{Jornadas Laborales:}

- Se logró el aumento de una hora no lectiva (rebajando una hora lectiva) a partir de 2002.

- En las escuelas con jornada escolar completa se trabajaran 38 semanas en lugar de 40

- Transparencia y objetividad en sumarios

- Reducción del número de alumnos por curso de 45 a 40 en los sectores más pobres.

- Establecio nuevas normas sobre perfeccionamiento.

\section{Reglamentarias:}

- Implementación de una Comisión Nacional Tripartita (Ministerio de Educación, Colegio de Profesores y Asociación de Municipios) que trabajó durante seis años para elaborar un Sistema Nacional de Evaluación del Desempeño, que reemplazara el sistema de calificaciones establecido en el Estatuto Docente, con participación del Colegio de Profesores, la propuesta final consensuada entre las partes fue llevada a consulta a la base del magisterio, siendo aprobada por el $70 \%$ del profesorado.. Perfeccionamiento del reglamento de concursos, obligando a los empleadores a llenar cada año los cargos vacantes con titularidad.

- El Congreso Nacional de Educación de 1997, presento varias propuestas en los diferentes órdendes de la actividad educativa; siendo quizás una de las más importantes, que se tradujo en modificación de la política pública educativa, que incidio en la transformación experimentada por el sistema educacional en Chile la cual se ha traducido en un crecimiento acelerado del sector privado con o sin aporte estatal, por sobre la evolución que muestra el sector municipal

- Cambio de un sistema de calificaciones del desempeño por un sistema de evaluación de los profesionales de la educación, sea cual sea su jerarquía, ámbito de trabajo y nivel de responsabilidad.

- Legislación sobre enfermedades profesionales

- Para el año 2000, el sistema educacional había mostrado su ánimo de transformación, lo cual se logró aumentando y diversificando la oferta educativa en todos los niveles, dejando al Estado chileno, prácticamente en el papel arbitral respecto a éste nuevo renglón económico, en el que ahora, primaría, la competencia perfecta.

Fuente: Elaboración propia a partir de revisión de (CLACSO 2005: Pg. 14 -18) 


\section{Cuarto Momento: La Educación Chilena en el Siglo XXI}

Con relación a los cambios que experimento Chile en esta etapa de concertación, en cuanto al fortalecimiento de su sistema educativo, el país asumió un importante reto, incorporándose a lo propuesto por la UNESCO para el 2000, planteó 6 objetivos que la tarea educativa debía llevar a cabo para el año 2015, los cuales posteriormente fueron verificados de acuerdo con el grado de cumplimiento de los 164 países firmantes, entre los cuales se encuentra Chile, como resultado se publicó el Informe de seguimiento de la Educación para Para Todos en el Mundo, 2000-2015; logros y desafíos. (2015).

Con relación a los objetivos, se establece a continuación los temas que aborda cada uno, para lo cual se presenta a continuación los aspectos más relevantes de cada uno de los objetivos planteados especialmente en el caso de Chile de acuerdo con lo señalado por el informe de DAKAR UNESCO (2015)

1. Atención y educación de la primera infancia: En Chile, se proporciona enseñanza preescolar por conducto de una combinación de proveedores públicos y proveedores privados subvencionados por el Gobierno; en 2011, las subvenciones gubernamentales recibidas por todos los alumnos matriculados aumentaron un $15 \%$, a lo que se sumó un objetivo de escolarización universal de los niños de 4 y 5 años de edad de los tres quintiles de ingresos más bajos antes de que finalizara 2014 (OCDE, 2013). El gasto público en enseñanza preescolar, como proporción del PNB, se duplicó, pasando de un 0,3\% en 1999 a un $0,6 \%$ en 2012. En 2002, (UNESCO: 287)

2. Enseñanza primaria universal: En cuanto a la enseñanza primaria universal, Chile ha observado un leve incremento en los costos educativos, por supuesto, como consecuencia de los fenómenos de privatización; aunque el costo sigue siendo bastante bajo comparado con los demás países, lo que indica que Chile continuó con sus procesos de escolarización y aumento de cupos escolares.

3. Competencias de jóvenes y adultos: En cuanto a la educación de jóvenes y adultos se ve que hay un propósito serio a nivel mundial para lograr mejores niveles de capacitación en estos grupos poblacionales, especialmente cuando llevan tiempo desescolarizados. Sin embargo, queda la duda si es por filantropía o para tener mano de obra mejor calificada a la que se le pagan los más bajos salarios. 
4. Alfabetización de los adultos: El informe advierte que la alfabetización de adultos ha bajado en intensidad y calidad. Sin embargo, hace referencia algunos programas estatales en la materia, que muestra la seriedad con la que algunos países asumen esos compromisos. En Chile se trata de la Campaña "Contigo Aprendo", vigente desde 2003.

5. Igualdad de Género: En lo referente a la igualdad de género, el informe muestra serias preocupaciones en la materia. Llega incluso a tocarla en temas anteriores, mostrando que el género se convierte en motivo de múltiple subordinación. En lo referente al sistema escolar, la tasa de matrícula, acceso y permanencia son preocupantes, por la discriminación y las imágenes que la división sexual del trabajo ha posicionado como estereotipos. "En Chile, ser madre reduce la probabilidad de culminar la educación secundaria entre un 24\% y un 37\% (Kruger y otros, 2009, en UNESCO: 2015: 196)

6. Calidad de la Educación: En cuanto a la Calidad de la Educación, el informe revive la polémica por los incentivos económicos que se ofrecen en el sistema educativo chileno. "En Chile, los datos de la evaluación nacional se utilizaron para analizar los efectos de los incentivos monetarios en el rendimiento escolar (Mizala y Urquiola, 2013 en UNESCO 2015: 222)

\section{BIBLIOGRAFÍA}

- Álvarez M. (2007), Líderes Políticos del siglo XX en América Latina, Ed. Lom, Santiago de Chile.

- Ansaldi, W. y Giordano, V. (2012) América Latina. La construcción del orden, Ariel, Buenos Aires, 2 tomos.

- Bergquist, C. (1988) Los Trabajadores en la Historia Latinoamericana, Siglo XXI Editores, Bogotá.

- Bulmer, V, (1998) La historia económica de América Latina desde de la independencia, Fondo de Cultura Económica, México DF.

- Casas, S. (2014). América Latina y el Campo Híbrido de la Sociología Histórica: una explicación de la larga duración. Conversación con Waldo Ansaldi y Verónica Giordano. En: revista de la Red Intercátedras de Historia de América Latina Contemporánea, (Segunda época), Año II, Nº 1, Córdoba, Junio de 2014. pp. 124 - 137.

- CLACSO (2005) Las Reformas Educativas en los Países del Cono Sur: un balance crítico Confederación de Trabajadores de la Educación de la República Argentina; Colegio de 
Profesores Chile; Confederación Nacional de Trabajadores de la Educación Brasil; Asociación de Funcionarios de la Universidad del Trabajo de Uruguay; Laboratorio de Políticas Pública LPP, Rio de Janeiro Buenos Aires

- Cockcroft, J. América Latina y Estados Unidos. Historia y política país por país, Siglo Veintiuno Editores, México DF, 2001.

- Halperín T. (1995) Historia Contemporánea de América Latina, Alianza Editorial, Madrid.

- Instituto Nacional de Evaluación Educativa. (2016). Panorama de la educación. Indicadores de la OCDE. Informe español. Ministerio de Educación, Cultura y Deporte. Madrid.

- Leibniz, G. (1923 y ss.). Sämtliche Schriften und Briefe, Berlin Akademie-Verlag, Darmstadt, Leipzig.

- Ley Orgánica Constitucional de Enseñanza, LOCE, en http://repositorio. historiarecienteenlaeducacion.com/items/show/3222

- Núñez, I. (1997). Historia Reciente de la Educación Chilena, en http://historiaeducacional. bligoo.com/media/users/4/207323/files/22267/HISTORIA_RECIENTE_DE_LA_ EDUCACION_CHILENA1.pdf.

- Programa de las Naciones Unidas para el Desarrollo. (2019). http://www.undp.org

- UNESCO. (2015). La educación para todos, 2000 - 2015: logros y desafíos. Informe de seguimiento. Paris; Tercer estudio regional comparativo y explicativo. Resumen ejecutivo, informe de resultados. Logros de aprendizaje. Laboratorio latinoamericano de evaluación de la calidad de la educación en http://es.unesco.org/gem-report/gem-reporthigher-education-policy-paper-social-media-resources 